\title{
Registro
}

\section{bibliográfico da \\ pesquisa em \\ comunicação no \\ Rio Grande do Sul cinema e fotografia}

Coordenação: Francisco R. Rüdiger

PFEIL, Jesus. "Antologia do Cinema Gaúcho - I". In: Cultura Contemporânea 1, (51-52) 1968.

PFEIL, Jesus. "Antologia do Cinema Gaúcho - II". In: Cultura Contemporânea 2, (97-99) 1968.

PFEIL, Jesus. "Antologia do Cinema Gaúcho - III". In: Cultura Contemporânea 3, (108-112) 1969.

FERREIRA, Athos Damasceno. "Fotógrafos de Porto A legreno Século XIX". In: Colóquios com Minha Cidade. Porto Alegre, Globo, 1974.

EXPERIÊNCIA, "Cinema Gaúcho: Pequena História de Pioneiros". Porto Alegre, nov. 75, pp. 6-7.

BECKER, Tuio. Cinema Gaúcho: Uma Breve História. Porto Alegre, Movimento, 1986. 111p.

MAINIERI, Flávio. "Cinema e Literatura: Narrativas Diferenciadas, Vidas Secas, Um Exemplo". Porto Alegre, Dissertação de Mestrado, Letras, UFRGS, 1986.

SELIGMAN, Flávia. "VerdesAnos do CinemaGaúcho - 0 Ciclo Super-8 em Porto Alegre". São Paulo, Dissertação de Mestrado, ECA/ USP, 1980.

CUNHA, João M. dos Santos. "A Hora da Estrela, do Livro ao Filme: A intersecção de duas narrativas". Porto Alegre, Dissertação de Mestrado, Letras, UFRGS, 1991.

PFEIL,Jesus. “O Cinematógrafo esualntrodução no Rio Grande do Sul em fins do Século XIX". Inédito s.d. [circa 1980]

PFEIL, Jesus. "Panorama do Cinema no Rio Grande do Sul" (notas). Inédito. s.d. [circa 1980]

PFEIL, Jesus. "Alemãas e Colônias Alemãs no Cinema". In: 
A nais do $2^{\circ}$ Simpósio de História da Imigração e Colonização Alemã no Rio Grande do Sul. São Leopoldo, Rotermund, s.d. [circa 1980].

\section{Comunicação e cultura}

FERREIRA, A thos Damasceno. Palcos, Salões e Picadeiros. Porto Alegre, Globo, 1956.

JACKS, Nilda A. "Mídia Nativa: Um Estudo sobre a Cultura Regional do RS e sua Relação com a Indústria Cultural". São Paulo, Dissertação de Mestrado, ECA / USP,1987.

FACHEL, Ondina. "A LeituraSocial daN ovela das Oito". Porto Alegre, Dissertação de Mestrado, Antropologia, UFRGS, 1986

JACKS, Nilda A. "A Recepção na Querência: Estudo de Audiência e da Identidade Cultural Gaúcha como Mediação Simbólica". São Paulo, Tese de Doutorado, ECA / USP, 1993.

CHAGAS, Míriam de Fátima. "Uma Mão Lava a Outra: A Interação de Grupos Populares com a Rádio Farroupilha". Porto Alegre, Dissertação Mestrado, Antropologia Social, UFRGS, 1993.

\section{Comunicação e poder}

GUARESCHI, Pedrinho. Comunicação e Poder: A Presença e 0 Papel dos Meios de Comunicação de M assa Estrangeiros na A mérica Latina. Petrópolis, Vozes,1988, 88p.

RAMOS, Roberto. Futebol: I deologia do Poder. Petrópolis, Vozes, 1984,114p.

WEBER, Maria Helena. "Ditadura e Sedução: Redes de Comunicação e Coerção no Brasil 1969/1974". Porto Alegre, Dissertação Mestrado, Sociologia, UFRGS,1994.

WAINBERG, Jacques A. "Newsreel Vocal Commentaries: Interpreting the World". South Carolina, Dissertação de Mestrado, 1990.

\section{Comunicação rural}

RUSSEL, Lloyd. 0 Uso dos M eios de Comunicação pelos Técnicos
Agropecuários do Estado do Rio Grande do Sul. Porto Alegre, IEPE/ UFRGS,1966.

BOSTIAN, Lloyd, OLIVEIRA, F. Influência da Educação e O utros Fatores naComunicação da Agricultores. Porto Alegre, IEPE/ UFRGS, 1965.

FLIEGEL, Friederick. Alfabetismo e Exposição à Informação Instrumentalentre Agricultores do Brasil Sul. Porto Alegre, IEPE/ UFRGS, 1967.

SCHNEIDER, Ivo. A nálise do Conteúdo Agrícola dos Jornais. Porto Alegre, IEPE/ UFRGS, 1969.

TROLLER, Neiva. 0 Papel da Comunicação Coletiva na M odernização dos A gricultores. Porto Alegre, IEPE/ UFRGS, 1969.

SCHNEIDER, Ivo. Teste da Hipótese do Fluxo Comunicativo em duas Etapas para a Difusão de Nova Informação Agrícola num País em D esenvolvimento. IEPE/ UFRGS, 1974.

FETT, John; TROLLER, Neiva; FRÖHLICH, Egon Roque. Fatores Associados com o Papel e U so da Comunicação Coletiva no D esenvolvimento Agrícola. Porto Alegre , IEPE/ UFRGS, 1974, $114 f$.

FRÖHLICH, Egon. Análise de Conteúdo dos Assuntos Agrícolas e sua Relevância Situacional no Jornais do Rio Grande do Sul. Porto Alegre, IEPE/ UFRGS,1970.

KRATZ, Ana Christina. Fórmulas para Estimar a Diferenciação de Leitura dosArtigos Agrícolas Publicados em Jornais Sul-riograndenses para Agricultores de Baixa Escolaridade. Porto Alegre, IEPE/ UFRGS, 1973.

AGRICULTURA \& COMUNICAÇÃO. 0 Colono no M undo da Informação. Porto Alegre, 29 (6 -14) 1978.

BOSTIAN, Lloyd, SCHNEIDER, Ivo. O Uso dos Meios de Comunicação pelos Técnicos Agropecuários do Estado. Porto Alegre, IEPE/UFRGS, s.d.

FETT, J. \& TROLLER, Neiva. Alfabetismo, Educação, Comunicação Coletiva e Administração de Práticas A grícolas. Porto Alegre, IEPE/ UFRGS, s.d.

QUESADA, Gustavo M. Comunicação e Comunidade: Mitos de M udança Social. São Paulo, Loyola, 1980, 94p 
SPANIOL, Enio Luiz . "Estudo dos Efeitos da Audiência da Telenoveladas Oitono Meio Rural do OesteCatarinense". Porto Alegre, Dissertação de Mestrado, Sociologia Rural, UFRGS, 1992.

SPERRY, Suzana. "O Olhar da Exclusão : Comunicação e Tecnologia de Poder na Pesquisa e Extensão Rural". Porto Alegre, Dissertação de Mestrado, Sociologia Rural, UFRGS, 1992.

\section{Meios de comunicação de massa}

ANDRÉ, Alberto. Ética da Comunicação Social: Doutrina e Código. Porto Alegre, FAMECOS/ PUC, 1970.

CAPARELLI, Sérgio. "OsM eios deComunicaçãono Rio Grande do Sul". In: Cadernos de Comunicação Proal 2 (90-94), 1977.

CAPARELLI, Sérgio. Ditaduras e Indústrias Culturais no Brasil, na Argentina, no Chile e no U ruguai. Porto Alegre, Editora da Universidade/ UFRGS, 1989.

CAPARELLI, Sérgio. Comunicação de massa sem massa. São Paulo,Cortez, 1980. 125p

SEMINÁRIO COMUNICAÇÃO ANOS 90. A integração do Cone Sul: documento final. Porto Alegre, FEPLAM, 1990. 89p. Pesquisa em comunicação

BERGER, Christa. "Panorama Bibliográfico da Pesquisa em Comunicação Popular eA Iternativa no Brasil". Cópia FABICO / UFRGS, (circa 1989).

CAPARELLI. "Avaliação e Perspectivas - 89". Comunicação Brasília. Cópia FABICO / UFRGS, CN PQ, 1989.

ESCOSTEGUY, Ana Carolina Damboriarena. "A Pesquisa do Popular na Comunicação: Uma Análise Metodológica". São Paulo, Dissertação de Mestrado, ECA / USP, 1993, 240f.

\section{Publicidade e Propaganda}

GOMES, Rita Soares. "Coleção de Anúncios do Diário de Porto Alegre em 1827". In: A nais do III Congresso Sul-riograndense de História e Geografia. Porto Alegre, Pref. Municipal, Globo, 1940, Vol. 1, pp. 81-106.
SILVEIRA, Carlos Cauby. “Episódios da Propaganda Gaúcha Até 0 Finalda Década de 50". In: Cadernos da ARP 1, Dezembro de 1974.

GRAEFF, Telisa Furlametto. Função Conotativa e Comunicação V erbal na Publicidade. Porto Alegre, Letras, UFRGS, 1978, $172 f$.

MULLER, Lúcia Helena Alves. "A Alma do Negócio : Um Estudo Antropológico sobre o uso da Pesquisa de Mercado na Publicidade". Porto Alegre, Dissertação de Mestrado, Antropologia, UFRGS, 1989, $293 f$.

BOCCHESE, Jocelyne da Cunha. Sujeito Polifônico e Argumentação no Editorial e na Publicidade. Porto Alegre, 1993, 286f.

RAMOS, Roberto. Grã-finos na Globo: Cultura e M erchandising nas N ovelas. Petrópolis, Vozes, 1991, 128p.

PERUZZOLO, A. (org). 0 Corpo Semiotizado. Porto Alegre, EST, 1994.

\section{Relações Públicas}

SIMÕES, Roberto Porto; WENDHAUSEN, Eugênia da Silva. Introdução a Relações Públicas: Guia Didático. Porto Alegre, FAMECOS / PUCRS, 1974, 116p.

AZEVED0, Martha Alves D'. Relações Públicas: Teoria e Processo. Porto Alegre, Sulina, 1971, 334p.

CICLODEINTEGRAÇÃODERELAÇÕESPÚBLICAS(3).Anais e Relatórios: Departamento de Relações Públicas.Porto Alegre, PUC, 1976, 80p.

KASPER, Rejane. Informação e O pinião Pública. Porto Alegre, 1984, 6lf.

SIMÕES, Roberto Porto. Relações Públicas: Função Política. NovoHamburgo: FEEVALE, 1984, 134p.

VINADÉ, Gelson Airton Mesquita. Relações Humanas e Públicas. Porto Alegre, CORAG, 1983, 50p.

FREITAS, Antonio de Lisboa Mello. Relações Públicas: Casos A tuaisPerspectivas Futuras. Porto Alegre, Sulina, 1985, 133p.

ALBUQUERQUE, Adão Eunes. Planejamento das Relações 
Públicas. Porto Alegre, Acadêmica, 1981, 109p.

WENDHAUSEN, Eugênia da Silva. Projeto de Vida para a Ilha Grande dos M arinheiros: U ma Experiência Integrada em Relações Públicas, Educação,Trabalho e Ação Comunitária (19861990). Porto Alegre, 1990, 432f.

FONSECA, Ana Maria. "A Relação entre percepções e comunicaçãointerna em organizações em mudança". Porto Alegre, Dissertação de Mestrado, Faculdade de Ciências Econômicas, Pós-Graduação e Administração, UFRGS, 1991.

MOURA, Cláudia Peixoto de. Situação do Comunicador Social em Formação: Um Estudo de Caso. Porto Alegre, FAMECOS/ PUCRS, 1990, 286f.

\section{Teorias da comunica ção}

GUARANY, Wilson Chrisosostmo; BENTZ, Ione M.G. M etacomunicação. Bento Gonçalves, Campus, 1975, 150p.

PERUZZOLO, Adair Caetano . Comunicação e Cultura. Porto Alegre, Sulina, 1972, 388p.

AZEVEDO, Marcelo Casado D'. Atenção, Signos, Graus de Informação (coord.). Porto Alegre, Editora da UFRGS, 1973.

AZEVED0, Marcelo Casado D'. Comunicação, Linguagem e A utomação (coord.). Porto Alegre, Editora da UFRGS, 1970.

AZEVEd0, Marcelo Casado D'. Pensamento, Código, Informação (coord). Porto Alegre, Editora da UFRGS, 1972.

AZEVEDO, Marcelo Casado D'. Teoria da Informação: FundamentosBiológicos, Teó-ricos e Matemático, Relações com a Cultura de M assa. Petrópolis,Vozes, 1971.

PAVIANI , Jayme. A Arte na Era da Indústria Cultural. Porto Alegre, PyR, 1987, 100p.

RÜDIGER, Francisco Ricardo. Estética da Cultura de Massa. Porto Alegre, [s.n.], 1990.

\section{Rádio e televisão}

FORNARI, Ernani. 0 Incrivel Padre Landell de M oura. Porto Alegre, Globo, 1960.
ANAVATE, Henrique. "Telecomunicações no Rio Grande do Sul". In: 40 Curso de Alto Nível para Jornalistas. Porto Alegre, UFRGS/ ARI, 1974, pp. 141-148.

CAUDURO, Fernando. 0 Homem que apertou 0 botão da Comunicação.Porto Alegre, FEPLAM, 1977, 2ed.

SIROTSKI, Maurício. "Situação ePerspectivas da Comunicação Social no RioGrande do Sul". In: 40 Curso de Alto Nível para Jornalistas. Porto Alegre, UFRGS/ ARI,1974, pp. 95-106.

VAMPRÉ, Octavio Augusto. Raízes e Evolução do Rádio e da Televisão. Porto Alegre, FEPLAM, 1979, 276p.

FISCHER, Rosa Maria Bueno. 0 M ito na Sala de Jantar: Leitura Interpretativa do Discurso Infanto-Juvenil sobre TV. Porto Alegre, Movimento, 1984.

HAUSSEN, Doris Fagundes. "Rádio e Criança: Um Estudo Sobre a Ausência de Programação Infantil nas Emissoras de Porto Alegre". São Paulo, Dissertação deM estrado, ECA / USP, 1988, 207f.

UNIVERSIDADE FEDERAL DO RIO GRANDE DO SUL. PróReitoria deExtensão. Departamento de Comunicação. Cultura e Educação: 0 Papel da Rádio da Universidade Federal do Rio Grande do Sul - U ma Pesquisa de Audiência e de O pinião.Porto Alegre, Editora da Universidade, 1981, 158p.

HERZ, Daniel. A história Secreta da Rede Globo. Porto Alegre, Tchê, 1987, 301p

BUEN0, Zith. A Televisão no Brasil: Seu Desenvolvimento e Poder. PortoAlegre, 1983, 62f.

HAUSSEN, DorisFagundes. "RádioePolítica:TemposdeVargas ePerón". São Paulo, Tese de Doutorado ECA / USP, 1992, 324f.

\section{Nota}

Este levantamento, embora tenha procurado vasculhar a totalidade da produção no campo presente, não é de forma alguma exaustivo e completo, seja devido a precariedade das nossas bibliotecas, seja pelas próprias limitações dos autores. Desculpamo-nos deantemão pelas eventuaisomissões defontes e referências existentes, sendo que toda contribuição sobre novos títulos será bem recebida. 